\title{
THE BIRTH PROCESS MAKES THE IMMATURE SMALL INTESTINE SENSITIVE TO FEEDING-INDUCED INTESTINAL DISEASE
}

\author{
Charlotte R. Bjørnvad, Yvette M. Petersen, Mette Schmidt, Jan Elnif \& Per T. Sangild
}

Animal Nutrition and Reproduction, Royal Veterinary and Agricultural University, Frederiksberg C,

DK-1870, Denmark

Many newborn animals suffer from severe intestinal disease in the immediate postnatal period. We have shown that such disease is particularly prevalent when animals are born prematurely and fed a milk-placer (in stead of mother's colostrum). By feeding a milk-replacer to fetuses in utero and comparing them with corresponding pigs fed ex utero, we tested the hypothesis that the response of the immature intestine to oral feeding depends on the process of birth. Under anaesthesia, eight fetuses in 2 pregnant sows $(105-106 \mathrm{~d}$ gestation, term $=115 \mathrm{~d})$ were prepared with a feeding tube inserted into the fetal esophagus. After the operation, the fetuses were fed either sow's colostrum $(n=4)$ or a milk-replacer (formula, $\mathrm{n}=4$ ) for $24 \mathrm{~h}$ while in utero $(15 \mathrm{ml} / \mathrm{kg} / 3 \mathrm{~h}$ ). After the $24 \mathrm{~h}$ feeding, the operated fetuses were removed from the sows by caesarean section and killed for tissue collection. From these and some other pregnant sows (105-107 d gestation) we also removed some unoperated control fetuses. These were either killed at birth (no feed, $n=4$ ) or postnatally after $24 \mathrm{~h}$ of feeding (colostrum, $\mathrm{n}=7$, formula, $\mathrm{n}=8$ ). Results from all 5 treatment groups are shown below.

Table. Intestinal growth and enzyme activities in premature pigs fed colostrum or formula, either as fetuses or newborns (mean values $\pm \mathrm{SE}$ for 3 intestinal regions). ${ }^{*} \mathrm{P}<0.05$, higher value in colostrumfed pigs than in corresponding formula-fed pigs.

\begin{tabular}{llclll}
\hline & Control & \multicolumn{2}{c}{ Premature fetal pigs } & \multicolumn{2}{c}{ Premature newborn pigs } \\
& No feed & Colostrum & Formula & Colostrum & Formula \\
\hline Intestine (g/kg) & $21.2 \pm 2.1$ & $33.9 \pm 2.7$ & $30.9 \pm 2.8$ & $33.9 \pm 0.8$ & $31.2 \pm 1.8$ \\
Mucosa (\%) & $62.6 \pm 3.2$ & $80.0 \pm 3.5$ & $76.6 \pm 1.6$ & $83.1 \pm 1.2^{*}$ & $73.4 \pm 1.3$ \\
Maltase (U/g) & $0.76 \pm 0.06$ & $2.54 \pm 0.27^{*}$ & $1.49 \pm 0.21$ & $3.05 \pm 0.14^{*}$ & $1.08 \pm 0.12$ \\
Lactase (U/g) & $14.5 \pm 2.2$ & $9.4 \pm 1.0$ & $10.2 \pm 1.1$ & $9.09 \pm 1.03^{*}$ & $3.81 \pm 0.43$ \\
ApN (U/g) & $4.31 \pm 0.31$ & $3.29 \pm 0.18$ & $4.40 \pm 0.38$ & $5.15 \pm 0.47^{*}$ & $2.62 \pm 0.30$ \\
ApA (U/g) & $1.86 \pm 0.14$ & $2.51 \pm 0.10$ & $3.19 \pm 0.18$ & $3.31 \pm 0.26^{*}$ & $1.68 \pm 0.20$ \\
DPP IV (U/g) & $1.55 \pm 0.18$ & $0.61 \pm 0.13$ & $0.78 \pm 0.13$ & $1.48 \pm 0.21^{*}$ & $0.76 \pm 0.09$ \\
\hline
\end{tabular}

The results show that fetal pigs and newborn pigs differ markedly in their response to feeding. Feeding increased the relative mass of the intestine in all groups ( $+50-60 \%)$, but only in newborn pigs did formula-feeding induce marked decreases in mucosal mass and enzyme function, relative to colostrum-feeding. Thus, exposure of the immature intestine to a milk-placer is associated with intestinal mal-function, only if the animal is born. Probably, the detrimental effects of formula-feeding depend on the birth transition and the associated bacterial colonization and changes in blood and oxygen supply. 